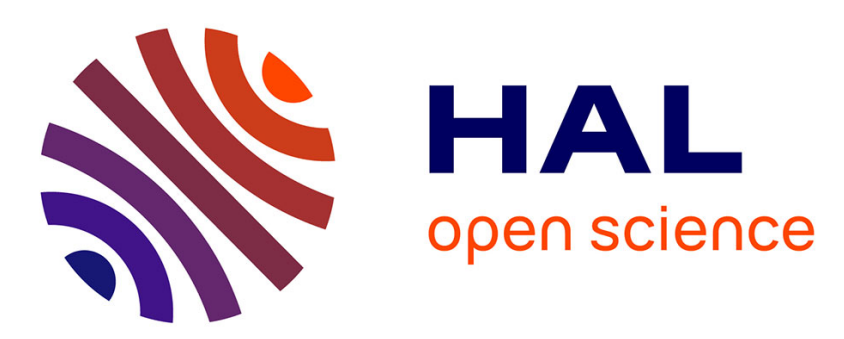

\title{
Honey bees and bumble bees respond differently to inter- and intra-specific encounters
}

Shelley Rogers, Peter Cajamarca, David Tarpy, Hannah Burrack

\section{To cite this version:}

Shelley Rogers, Peter Cajamarca, David Tarpy, Hannah Burrack. Honey bees and bumble bees respond differently to inter- and intra-specific encounters. Apidologie, 2013, 44 (6), pp.621-629. 10.1007/s13592-013-0210-0 . hal-01201330

\section{HAL Id: hal-01201330 \\ https://hal.science/hal-01201330}

Submitted on 17 Sep 2015

HAL is a multi-disciplinary open access archive for the deposit and dissemination of scientific research documents, whether they are published or not. The documents may come from teaching and research institutions in France or abroad, or from public or private research centers.
L'archive ouverte pluridisciplinaire HAL, est destinée au dépôt et à la diffusion de documents scientifiques de niveau recherche, publiés ou non, émanant des établissements d'enseignement et de recherche français ou étrangers, des laboratoires publics ou privés. 


\title{
Honey bees and bumble bees respond differently to inter- and intra-specific encounters
}

\author{
Shelley R. Rogers, Peter Cajamarca, David R. Tarpy, Hannah J. Burrack \\ Department of Entomology, North Carolina State University, Raleigh, NC 27695, USA
}

Received 8 November 2012 - Revised 1 April 2013 - Accepted 12 April 2013

\begin{abstract}
Multiple bee species may forage simultaneously at a common resource. Physical encounters among these bees may modify their subsequent foraging behavior and shape pollinator distribution and resource utilization in a plant community. We observed physical encounters between honey bees, Apis mellifera, and bumble bees, Bombus impatiens, visiting artificial plants in a controlled foraging arena. Both species were more likely to leave the plant following an encounter with another bee, but differed in their responses to intra- and inter-specific encounters. A. mellifera responded similarly to an encounter with either species. However, most $B$. impatiens that encountered $A$. mellifera discontinued foraging at the observed plant, but exhibited only a slight decrease in foraging following an intraspecific encounter. Interactions between bees that elicit changes in foraging behavior may have important implications for the pollination of wild and managed plants.
\end{abstract}

\section{Apis / Bombus / competition / interspecific avoidance / pollination}

\section{INTRODUCTION}

Bees visit flowering plants for nectar and pollen resources. The community of bees foraging at a particular plant population is shaped by multiple interacting factors. These include biogeography and seasonal phenology of bee species (Mitchell 1960, 1962; Michener 1979), temporal foraging patterns (Eickwort and Ginsberg 1980), the availability and distribution of nesting habitat in the landscape (SteffanDewenter et al. 2002; Williams et al. 2010), the relative attractiveness and accessibility of a plant population's nectar and pollen resources (e.g., Dedej and Delaplane 2005; Newman and Thomson 2005), and the presence of coflowering plants in the landscape, which may attract and compete with the target plant

Corresponding author: S.R. Rogers,

shelleyrogers@eml.cc

Manuscript editor: James Nieh population for pollinators (Feinsinger 1987; Westphal et al. 2003; Feldman et al. 2004; Williams and Kremen 2007). Potentially important, though less well understood, is how encounters between bees (of same and different species) visiting a common floral resource affect the subsequent foraging behavior of bees and, in turn, shape the community of foragers at a particular resource.

Bees may alter their patterns of flower visitation and resource utilization in response to other individuals in their community. The presence of a bee at a floral resource may serve as a cue, indicating the profitability of that resource to other bees ("local enhancement"; Leadbeater and Chittka 2005; Kawaguchi et al. 2006; Baude et al. 2008), including heterospecifics (Dawson and Chittka 2012). Conversely, competition between bee species foraging at a shared resource may result in restricted foraging or displacement. For instance, Inouye (1978) and Morse (1982) found that individual bumble bees (Bombus spp.) 
exhibited niche partitioning and shortened foraging bouts in the presence of heterospecifics. Similarly, in tropical stingless bees, Lichtenberg et al. (2010) showed that interspecific encounters at feeder stations facilitated the dominance of certain species and the displacement of others. Though most studies have highlighted the response of foragers to interactions with heterospecifics, Makino and Sakai (2005) and Fontaine et al. (2008) demonstrated that some Bombus spp. alter their foraging area and diet breadth in the presence of conspecifics.

Encounters between foraging bees may be particularly common (and impactful) in agricultural settings where the importation of managed bees (particularly honey bees, Apis mellifera L.) can result in a high density of foragers per floral resource. In squash and watermelon crops, for example, Pinkus-Rendon et al. (2005) found that contact between heterospecific bees often resulted in local displacement, with certain species being displaced more often than others. In sunflower, Greenleaf and Kremen (2006) found that $A$. mellifera were three times more likely to move between rows of male and female cultivars after interacting with a wild bee and, in doing so, enhanced the transfer of pollen and their per-visit pollination efficiency.

A. mellifera and B. impatiens are two of the most commonly managed bee species used as augmentative pollinators throughout the temperate zones of North America (Delaplane and Mayer 2000). Resultantly, these species frequently co-occur in high densities in agricultural settings (e.g., North Carolina blueberry systems; Rogers 2012). Encounters between $A$. mellifera and $B$. impatiens may have important ramifications for pollinator performance and subsequent pollination, yet little is known about how these species respond to interactions with one another. Based on the findings of previous research (Greenleaf and Kremen 2006; Lichtenberg et al. 2010), we expected that both $A$. mellifera and $B$. impatiens would reduce their foraging activity at a plant following an encounter with a heterospecific but not conspecific encounter. To test this prediction, we observed both species in a controlled foraging environment with artificial plants.

\section{MATERIALS AND METHODS}

We established three experimental foraging arenas in a hoop house covered with $70 \%$ woven shade cloth, then placed 10 feeding stations, designed to simulate plants, per arena (Figure 1a). Each "plant" consisted of a foraging platform with five "flowers" (1.5-mL Eppendorf tubes) inserted in a florist foam block covered by a yellow card (Figure 1b). Darkblue petals were printed beforehand on each card in a ring of four petals, with the Eppendorf tube being inserted in the center. We elevated foraging platforms on 1-m wooden dowels.

From 12 to $24 \mathrm{~h}$ before experiments, we placed either one five-frame nucleus colony of Apis ( $\sim 10,000$ bees per colony), three Bombus colonies ( $\sim 30$ to 40 bees per colony; Research Hive-Mini, Koppert Biological Systems, Inc., Howell, MI, USA), or a combination of Apis and Bombus colonies in an experimental foraging arena (Table I). A different colony of Apis was used for each experimental trial in which they were included; however, Bombus colonies, limited in number, were rotated throughout experimental arenas. To train bees to the plants, we added $\sim 0.5 \mathrm{~mL}$ of 2-M sucrose solution scented with $1 \%(\mathrm{v} / \mathrm{v})$ peppermint oil to each flower. At the start of data collection, we replaced the foraging platform from each plant, so that the new flowers contained 5$\mu \mathrm{L}, 2-\mathrm{M}$ scented sucrose solution (a field-relevant volume of nectar; e.g., Vaccinium ashei; Dedej and Delaplane 2005). For $30 \mathrm{~min}$ following the placement of new foraging platforms, we recorded foraging activity at three plants per arena (at plants 3, 7, and 9 in Figure 1a) using video cameras placed within $1 \mathrm{~m}$ of plants (Bloggie Touch Camera; Sony Corporation of America, New York, NY, USA).

We conducted foraging observations five times (Table I). Between sampling days, colonies were placed outside of the hoop house and allowed to forage normally. Because forager number varied by bee colony, we estimated bee density for each trial. We counted the number of Apis and Bombus observed at each recorded plant for $30 \mathrm{~s}$ at each of five 5-min intervals (i.e., at 5, 10, 15, 20, and $25 \mathrm{~min}$ ). We then calculated the density of bees per 

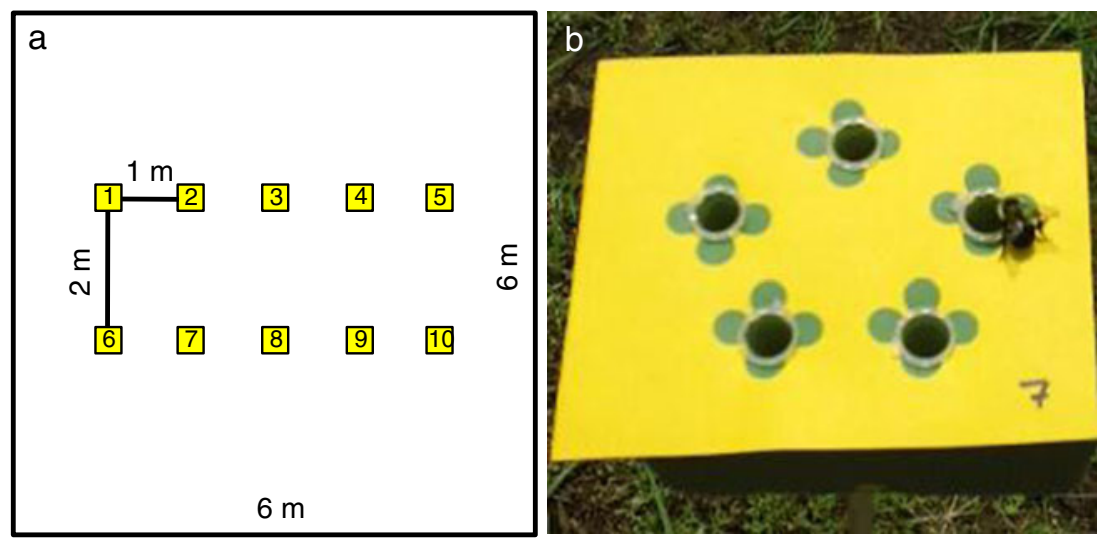

Figure 1. Foraging arena setup (a) with 10 artificial plants. Video cameras recorded bee activity at plants 3, 7, and 9. Surface of one artificial plant composed of five flowers (b) with Bombus inspecting flower.

plant per minute for each trial (Table I). Though adjacent arenas were sealed off with shade cloth, Bombus penetrated into arenas without Bombus colonies. Hence, bee density is more representative of the foraging community in an arena than number of colonies (e.g., Table I, Trial 2).

From each video recording, we transcribed the sequence of bee activity (defined in Table II) that took place on the foraging platform and within flowers. It was not possible for us to track the movement of individual bees throughout the arena and thus each individual record was parsimoniously assumed to be an independent observation. Based on this assumption, we first performed a chi-squared analysis of all bee activity records to determine if a physical encounter affected the likelihood of a bee's next recorded activity: continuing to forage, leaving the plant, or engaging in flower inspection at the same plant. We analyzed the subsequent action for both bees involved in an encounter. Because we observed a single population of bees in each trial, we performed a second chi-squared analysis on the trial averages to account for the possibility that bee activity records were not independent. The first analysis of all bee records provides for more statistical power, while the latter analysis by observational unit hedges against pseudo-replication. Below we distinguish the results of these two analyses with "by bee" and "by trial."

\section{RESULTS}

In $7.5 \mathrm{~h}$ of total recorded activity, we observed Apis engaged in 237 foraging events and 367 flower inspections and Bombus engaged in 223 foraging events and 365 flower inspections. We observed 82 instances of Apis bees encountering other Apis, 30 instances of Apis encoun-

Table I. Date, arena, colony abundance, and bee density per trial (30-min observation) of bee activity.

\begin{tabular}{|c|c|c|c|c|c|c|}
\hline \multirow[t]{2}{*}{ Trial } & \multirow[t]{2}{*}{ Date } & \multirow[t]{2}{*}{ Foraging arena } & \multicolumn{2}{|c|}{ Number of colonies } & \multicolumn{2}{|c|}{ Bee density (bees $\min ^{-1}$ plant $^{-1}$ ) } \\
\hline & & & Apis & Bombus & Apis & Bombus \\
\hline 1 & 15 Apr 2011 & 3 & 1 & 0 & 2.6 & 0.0 \\
\hline 2 & 2 May 2011 & 3 & 1 & 0 & 1.2 & 1.5 \\
\hline 3 & 15 Apr 2011 & 2 & 1 & 4 & 3.6 & 0.4 \\
\hline 4 & 2 May 2011 & 1 & 0 & 3 & 0.0 & 1.1 \\
\hline 5 & 2 May 2011 & 1 & 0 & 3 & 0.0 & 0.8 \\
\hline
\end{tabular}


Table II. Classification and description of bee activity observed at "plants".

\begin{tabular}{ll}
\hline Activity & Description \\
\hline Arrival & $\begin{array}{l}\text { Bee alights on "plant" } \\
\text { Forage }\end{array}$ \\
$\begin{array}{l}\text { Bee enters "flower" completely so that the apex of the metasoma is not visible; the length of } \\
\text { each forage constitutes the "floral handling time" } \\
\text { Encounter }\end{array}$ & $\begin{array}{l}\text { Bee comes into physical contact or close proximity }(<1 \mathrm{~cm}) \text { of a con- or heterospecific bee } \\
\text { Flower inspection } \\
\text { Bee circles or enters "flower" partially (head or mesosoma only) } \\
\text { Bee flies away from "plant" }\end{array}$ \\
\hline
\end{tabular}

tering Bombus, and 14 instances of Bombus encountering other Bombus (Table III). Consistent with field-collected data, Apis spent nearly twice as long inside flowers as Bombus (Table III; Cane and Payne 1988; Dedej and Delaplane 2005).

Individuals of either species that interacted with another bee, regardless of its identity, exhibited a trend toward decreased foraging and increased movement away from the plant compared with bees that had just foraged (Apis, by bee $-\chi_{1,260}^{2}=17.6, P<0.00001$; Apis, by trial- $\chi_{1,2}^{2}=2.6, P=0.10$, Figure 2a; Bombus, by bee- $\chi_{1,176}^{2}=17.5, P<0.0001$; Bombus, by trial- $\chi_{1,4}^{2}=3.7, P=0.05$, Figure $2 b$ ). After encountering another individual, Apis tended to increase flower inspection, and Bombus tended to decrease flower inspection, though this trend was only significant for Apis at the level of the individual (Apis, by bee- $\chi_{1,371}^{2}=5.0, P=0.02$; Apis, by trial- $\chi_{1,4}^{2}=1.0, P=0.32$, Figure $2 \mathrm{a}$; Bombus, by bee- $\chi_{1,256}^{2}=2.7, P=0.10$; Bombus, by trial- $\chi_{1,3}^{2}=0.6, P=0.42$, Figure $2 b$ ).

Apis and Bombus responded differently to intraand inter-specific encounters. Apis that encountered Bombus or other Apis were equally likely to leave the plant, continue foraging, or inspect flowers (Apis, by bee $-\chi_{2,187}^{2}=0.01, P=1.0$; Apis, by trial- $\chi_{2,2}^{2}=0.01, P=1.0$, Figure 2a). Bombus, however, stopped foraging at the observed plant altogether after an encounter with Apis, while exhibiting only a small decrease in foraging after intraspecific contact (Bombus, by bee $-\chi_{1,57}^{2}=$ 10.7, $P=0.001$; Bombus, by trial- $\chi_{1,3}^{2}=4.8$, $P=0.03$, Figure $2 \mathrm{~b}$ ). Following a heterospecific encounter, no Bombus continued foraging at the focal plant (Figure 2b), even beyond the next recorded activity.

Table III. Frequency of bee encounters, foraging events, and flower inspections, and floral handling time per trial.

\begin{tabular}{|c|c|c|c|c|c|c|c|c|c|}
\hline \multirow[t]{2}{*}{ Trial } & \multicolumn{3}{|c|}{ Encounters $^{\mathrm{a}}$} & \multicolumn{2}{|c|}{ Foraging events } & \multicolumn{2}{|c|}{ Flower inspections } & \multicolumn{2}{|c|}{ Floral handling time (s) } \\
\hline & $A-A$ & $A-B$ & $B-B$ & Apis & Bombus & Apis & Bombus & Apis & Bombus \\
\hline 1 & 5 & 0 & 0 & 39 & 0 & 39 & 0 & $7 \pm 1$ & - \\
\hline 2 & 11 & 15 & 3 & 53 & 42 & 53 & 42 & $7 \pm 1$ & $3 \pm 1$ \\
\hline 3 & 66 & 15 & 0 & 145 & 23 & 145 & 23 & $4 \pm 1$ & $8 \pm 1$ \\
\hline 4 & 0 & 0 & 10 & 0 & 108 & 0 & 108 & - & $3 \pm 1$ \\
\hline 5 & 0 & 0 & 1 & 0 & 50 & 0 & 50 & - & $4 \pm 1$ \\
\hline Total & 82 & 30 & 14 & 237 & 223 & 367 & 365 & $7 \pm 1^{\mathrm{b}}$ & $4 \pm 1^{\mathrm{b}}$ \\
\hline
\end{tabular}

${ }^{\mathrm{a}} A-A$ denotes encounters between Apis; $A-B$, encounters between Apis and Bombus; $B-B$, encounters between Bombus.

${ }^{\mathrm{b}}$ Means, rather than sums, are presented here for aggregate floral handling time 

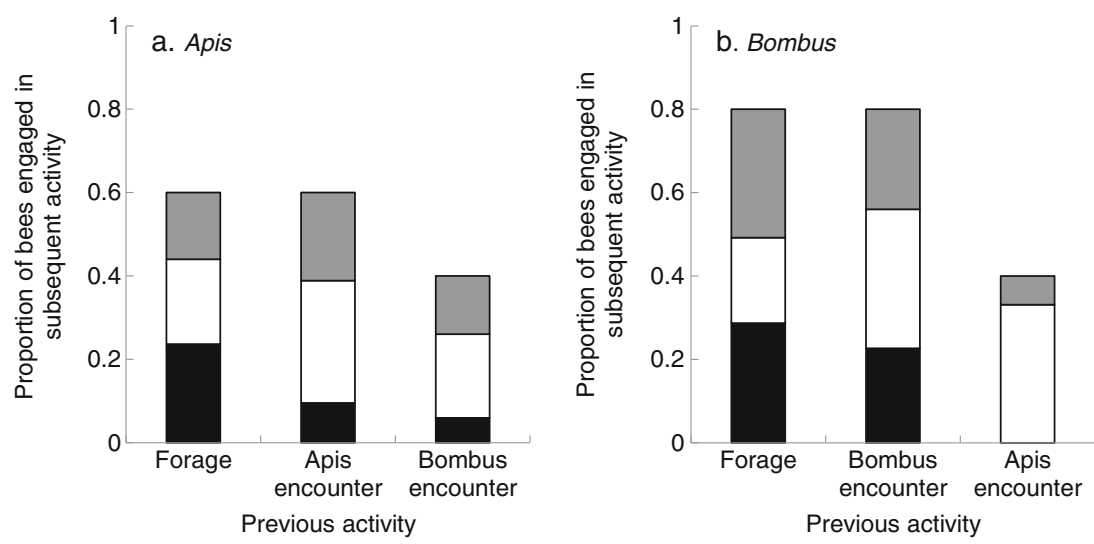

Figure 2. Proportion of (a) Apis and (b) Bombus that continued foraging (black), left the "plant" (white), or inspected "flowers" (gray) following either a foraging event or an encounter with a con- or heterospecific bee. Proportions represent trial averages, and thus do not sum to 1 .

\section{DISCUSSION}

Our results show that when a foraging bee encounters another bee, it is more likely to move from the shared resource than if it does not encounter another bee. The frequency of this displacement depends on the identity of both bees involved in the interaction. Bombus exhibited drastic changes in foraging behavior following an interaction with Apis, while Apis responded similarly to both intra- and inter-specific encounters.

Interference competition (physical blocking or behavioral aggression), exploitative competition (real or inferred resource depletion), or both may help to explain why bees are more likely to leave a plant after meeting another bee. We did not observe any evident forms of behavioral aggression within or between species. A. mellifera are rarely aggressive toward other insects while foraging (reviewed in Goulson 2003, but see Jean 2005); we are not aware of any record of aggression by Bombus at flowers. Following an interspecific encounter, Bombus reduced foraging at the same plant suggesting they might have been more sensitive to interference competition.

Goodale and Nieh (2012) observed a similar asymmetry in the responses of $A$. mellifera and $B$. impatiens to (the hemolymph of) heterospecifics. As they suggested, this asymmetry may reflect differences in foraging strategy (group vs. solitary foragers), whether a bee is more likely to encounter con- or heterospecifics at flowers, and where bees receive most of their foraging information (from nestmates or heterospecifics). Because A. mellifera forage in groups (DonaldsonMatasci et al. 2013), communicate with nestmates about floral resources (Seeley 1986), and are more likely to encounter con- than heterospecifics while foraging, they may experience little or no selective pressure to distinguish and respond differently to these two groups. Bombus spp., on the other hand, forage solitarily and are generally less abundant. Thus, individual Bombus may experience interspecific encounters more frequently and receive greater benefit by distinguishing the information source (conspecific vs. heterospecific, or conspecific vs. A. mellifera) and adapting its response accordingly.

Our results are consistent with this hypothesis, which was also borne out in tropical bees (Lichtenberg et al. 2010), and if correct suggests that the majority of wild bee species in temperate North America may respond to encounters with $A$. mellifera in a similar fashion to $B$. impatiens. In a time of heightened concern over the potential impacts of introduced $A$. mellifera on native bees, it is important to emphasize that negative interactions at the plant level, as observed in this study and others, do not necessarily translate to reduced long-term 
fitness, but only indicate the potential for such (Goulson 2003; Paini 2004).

Because we used multiple colonies of Bombus, we anticipated finding higher levels of conspecific avoidance in Bombus than in Apis (with foragers originating from a common colony). However, our results show the opposite trend. While nestmate recognition has been documented in both species (Breed 1983; Foster 1992) and influences bee activity at the nest entrance (Downs and Ratnieks 2000), it may have little or no impact on bees at floral resources.

This study raises several key questions:

1. How important is physical contact between bees to foraging behavior, compared with other means of detection such as visual cues or the scent of an earlier forager's footprints? Bombus spp. infer resource profitability and depletion from the presence of both con- and heterospecific bees at feeding sites (Kawaguchi et al. 2007; Baude et al. 2011; Dawson and Chittka 2012). By placing dead bees wrapped in plastic on flowers, Kawaguchi et al. (2006) showed that bees use visual cues in local enhancement. However, while bees may be present at flowers for less than a minute, chemical evidence of their visit may last up to $40 \mathrm{~min}$ (Stout and Goulson 2001). Both Apis and Bombus use these cues (detected while hovering over the surface) to avoid recently visited flowers and improve foraging efficiency (Stout and Goulson 2001; Gawleta et al. 2005; Witjes and Eltz 2007; but see Leadbeater and Chittka 2011). In our study, foragers may have responded to some combination of cues (visual, chemosensory, and physical contact) operating at different spatial and temporal scales.

2. What is the frequency of bee encounters in field conditions? By introducing a high density of bees into arenas with limited foraging options, we artificially elevated the frequency of such interactions. In a similar amount of video footage $(10 \mathrm{~h})$ from three blueberry fields (stocked with 2-10 Apis colonies ha ${ }^{-1}$ ), we observed 67 instances of Apis foraging, with only one encounter between two Apis bees (Rogers, unpublished data). However, both Pinkus-Rendon et al. (2005) and Greenleaf and Kremen (2006) observed numerous interactions between Apis and wild bees at cucurbits and sunflowers, respectively. Interaction frequency may vary in response to floral morphology as the open morphology of cucurbits and especially sunflowers enables simultaneous visitation by multiple bees.

3. How do bees respond to being displaced through encounters? In our experiments, we did not track the movement of individual bees among plants, and thus do not know how foragers responded to encounters beyond the focal plant. In field conditions, displaced foragers may respond in several ways. They may (a) move to another plant within the same population and proceed to forage as before, (b) continue foraging within the same plant population but gradually alter spatial or temporal aspects of their activity (for instance, foraging at more peripheral flowers or later in the day), (c) shift to foraging at a different plant species, or (d) stop foraging for some period of time. The response of bees to physical encounters likely depends on aspects of the plant community (e.g., composition, floral morphology, plant density, and nectar and pollen resources), the forager community (e.g., composition, bee morphology, bee density, and metabolic requirements), and the interaction of the two (Inouye 1978; Potts et al. 2003; Raine and Chittka 2007; Thomson 1989; Baude et al. 2011).

These latter issues, encounter frequency and response to displacement, have important implications for pollination. At a low frequency, bee encounters that result in displacement may have a negligible impact on population-level foraging behavior and pollination. However, at higher frequencies, encounters that result in displacement may affect which flowers are visited, how frequently, and by whom. Pollination of the focal plant population may be improved if a more effective pollinator displaces one that is less effective or if a pollinator becomes more effective as a result of increased movement within the plant population (increasing the 
transfer of xenogamous pollen; Greenleaf and Kremen 2006; Sanchez-Lafuente et al. 2012). Conversely, pollination may be negatively impacted if a less-effective pollinator replaces a more effective one or if an important pollinator discontinues visiting the plant population altogether.

The effect of bee encounters on pollination may be multifarious, with as many possible outcomes as there are bees and systems (both agricultural and wild). Though evaluating pollination (in terms of fruit or seed set) with respect to bee encounter rates in the field is logistically complex (e.g., Greenleaf and Kremen 2006), additional studies that sample from the breadth of wild and agricultural systems would surely enlighten us as to the degree and diversity of potential impacts. Future experiments along these lines may become increasingly feasible with new technologies that aid in tracking bee movement among plants (Ohashi et al. 2010).

We show that between-bee encounters influence the foraging behavior of $A$. mellifera and $B$. impatiens, and that this response depends on the identity of the other forager (con- or heterospecific). Our findings suggest that Bombus spp. and other solitary-foraging wild bees that encounter $A$. mellifera may be locally displaced from the source of the encounter (the plant or inflorescence). However, the extent of this response and its impact on future foraging behavior is unknown. Encounters between foraging bees should be further studied in field settings so that we may understand their role in shaping the community of foragers visiting a plant population and their impact on pollination.

\section{ACKNOWLEDGMENTS}

We thank Edward Waked and Samantha Walker, who participated in experimental design and setup, and Jennifer Keller, who maintained bee colonies. Emily White helped transcribe video data and Vincent Toups assisted with data analysis. Fred Gould, Nick Haddad, and Michael Simone-Finstrom provided feedback on the manuscript. This study was supported by funding from a National Science Foundation Graduate Research Fellowship to S.R.R.

Les abeilles et les bourdons répondent différemment aux rencontres inter- ou intra-spécifique

Apis / Bombus / compétition / pollinisation/ comportement d'approvisionnement / évitement interspécifique

Honigbienen und Hummeln zeigen unterschiedliche Antworten bei inner- und zwischenartigen Zusammentreffen

Apis / Bombus / Wettbewerb / zwischenartige Vermeidung / Bestäubung

\section{REFERENCES}

Baude, M., Dajoz, I., Danchin, E. (2008) Inadvertent social information in foraging bumblebees: effects of flower distribution and implications for pollination. Anim. Behav. 76, 1863-1873

Baude, M., Danchin, E., Mugabo, M., Dajoz, I. (2011) Conspecifics as informers and competitors: an experimental study in foraging bumble-bees. Proc. R. Soc. B 278, 2806-2813

Breed, M. (1983) Nestmate recognition in honey bees. Anim. Behav. 31, 86-91

Cane, J.H., Payne, J. (1988) Foraging ecology of the bee Habropoda laboriosa (Hymenoptera, Anthophoridae), an oligolege of blueberries (Ericaceae, Vaccinium) in the southeastern United States. Ann. Entomol. Soc. Am. 81, 419-427

Dawson, E.H., Chittka, L. (2012) Conspecific and heterospecific information use in bumblebees. PLoS. One. 7, e31444

Dedej, S., Delaplane, K. (2005) Net energetic advantage drives honey bees (Apis mellifera L) to nectar larceny in Vaccinium ashei Reade. Behav. Ecol. Sociobiol. 57, 398-403

Delaplane, K.S., Mayer, D.F. (2000) Crop Pollination by Bees. CABI, Wallingford

Donaldson-Matasci, M.C., DeGrandi-Hoffman, G., Dornhaus, A. (2013) Bigger is better: honeybee colonies as distributed information-gathering systems. Anim. Behav. 85, 585-592

Downs, S., Ratnieks, F. (2000) Adaptive shifts in honey bee (Apis mellifera L.) guarding behavior support predictions of the acceptance threshold model. Behav. Ecol. 11, 326-333

Eickwort, G., Ginsberg, H. (1980) Foraging and matingbehavior in Apoidea. Annu. Rev. Entomol. 25, 421-446 
Feinsinger, P. (1987) Effects of plant-species on each other's pollination-is community structure influenced? Trends Ecol. Evol. 2, 123-126

Feldman, T., Morris, W., Wilson, W. (2004) When can two plant species facilitate each other's pollination? Oikos 105, 197-207

Fontaine, C., Collin, C.L., Dajoz, I. (2008) Generalist foraging of pollinators: diet expansion at high density. J. Ecol. 96, 1002-1010

Foster, R. (1992) Nestmate recognition as an inbreeding avoidance mechanism in bumble bees (Hymenoptera, Apidae). J. Kans. Entomol. Soc. 65, 238-243

Gawleta, N., Zimmermann, Y., Eltz, T. (2005) Repellent foraging scent recognition across bee families. Apidologie 36, 325-330

Goodale, E., Nieh, J.C. (2012) Public use of olfactory information associated with predation in two species of social bees. Anim. Behav. 84, 919-924

Goulson, D. (2003) Effects of introduced bees on native ecosystems. Ann. Rev. Ecol. Evol. Syst. 34, 1-26

Greenleaf, S.S., Kremen, C. (2006) Wild bees enhance honey bees' pollination of hybrid sunflower. Proc. Natl. Acad. Sci. U. S. A. 103, 13890-13895

Inouye, D. (1978) Resource partitioning in bumblebees experimental studies of foraging behavior. Ecology 59, 672-678

Jean, R.P. (2005) Quantifying a rare event: pollen theft by honey bees from bumble bees and other bees (Apoidea: Apidae, Megachilidae) foraging at flowers. J. Kans. Entomol. Soc. 78, 172-175

Kawaguchi, L.G., Kazuharu, O., Toquenaga, Y. (2007) Contrasting responses of bumble bees to feeding conspecifics on their familiar and unfamiliar flowers. Proc. R. Soc. B 274, 2661-2667

Kawaguchi, L.G., Ohashi, K., Toquenaga, Y. (2006) Do bumble bees save time when choosing novel flowers by following conspecifics? Funct. Ecol. 20, 239-244

Leadbeater, E., Chittka, L. (2005) A new mode of information transfer in foraging bumblebees. Curr. Biol. 15, 447-448

Leadbeater, E., Chittka, L. (2011) Do inexperienced bumblebee foragers use scent marks as social information? Anim. Cogn. 14, 915-919

Lichtenberg, E.M., Imperatriz-Fonseca, V.L., Nieh, J.C. (2010) Behavioral suites mediate group-level foraging dynamics in communities of tropical stingless bees. Insectes Soc. 57, 105-113

Makino, T.T., Sakai, S. (2005) Does interaction between bumblebees (Bombus ignitus) reduce their foraging area?: bee removal experiments in a net cage. Behav. Ecol. Sociobiol. 57, 617-622

Michener, C. (1979) Biogeography of the bees. Ann. Mo. Bot. Gard. 66, 277-347

Mitchell, T.B. (1960) Bees of the eastern United States. I. N. C. Agric. Exp. Stn. Tech. Bull. 141, 1-538
Mitchell, T.B. (1962) Bees of the eastern United States. II. N. C. Agric. Exp. Stn. Tech. Bull. 152, 1-557

Morse, D. (1982) Foraging relationships within a guild of bumble bees. Insectes Soc. 29, 445-454

Newman, D.A., Thomson, J.D. (2005) Effects of nectar robbing on nectar dynamics and bumblebee foraging strategies in Linaria vulgaris (Scrophulariaceae). Oikos 110, 309-320

Ohashi, K., D'Souza, D., Thomson, J.D. (2010) An automated system for tracking and identifying individual nectar foragers at multiple feeders. Behav. Ecol. Sociobiol. 64, 891-897

Paini, D.R. (2004) Impact of the introduced honey bee (Apis mellifera) (Hymenoptera: Apidae) on native bees: a review. Austral Ecol. 29, 399-407

Pinkus-Rendon, M., Parra-Tabla, V., Melendez-Ramirez, V. (2005) Floral resource use and interactions between Apis mellifera and native bees in cucurbit crops in Yucatan. Mexico Can. Entomol. 137, 441449

Potts, S., Vulliamy, B., Dafni, A., Ne'eman, G., Willmer, P. (2003) Linking bees and flowers: how do floral communities structure pollinator communities? Ecology 84, 2628-2642

Raine, N.E., Chittka, L. (2007) Flower constancy and memory dynamics in bumblebees (Hymenoptera: Apidae: Bombus). Entomol. Gen. 29, 179-199

Rogers, S. R. (2012) Pollination ecology of highbush blueberry agroecosystems. MS thesis, North Carolina State University, Raleigh, NC

Sanchez-Lafuente, A.M., Rodriguez-Girones, M.A., Parra, R. (2012) Interaction frequency and perinteraction effects as predictors of total effects in plant-pollinator mutualisms: a case study with the self-incompatible herb Linaria lilacina. Oecologia 168, 153-165

Seeley, T.D. (1986) Social foraging by honeybees: how colonies allocate foragers among patches of flowers. Behav. Ecol. Sociobiol. 19, 343-354

Steffan-Dewenter, I., Munzenberg, U., Burger, C., Thies, C., Tscharntke, T. (2002) Scale-dependent effects of landscape context on three pollinator guilds. Ecology $\mathbf{8 3}, 1421-1432$

Stout, J., Goulson, D. (2001) The use of conspecific and interspecific scent marks by foraging bumblebees and honeybees. Anim. Behav. 62, 183189

Thomson, J.D. (1989) Reversal of apparent feeding preferences of bumble bees by aggression from Vespula wasps. Can. J. Zool. 67, 2588-2591

Westphal, C., Steffan-Dewenter, I., Tscharntke, T. (2003) Mass flowering crops enhance pollinator densities at a landscape scale. Ecol. Lett. 6, 961965

Williams, N.M., Crone, E.E., Roulston, T.H., Minckley, R.L., Packer, L., et al. (2010) Ecological and life- 
history traits predict bee species responses to environmental disturbances. Biol. Conserv. 143, 2280-2291

Williams, N.M., Kremen, C. (2007) Resource distributions among habitats determine solitary bee off- spring production in a mosaic landscape. Ecol. Appl. 17, 910-921

Witjes, S., Eltz, T. (2007) Influence of scent deposits on flower choice: experiments in an artificial flower array with bumblebees. Apidologie 38, 12-18 